\title{
Expression of CCR6 in esophageal squamous cell carcinoma and its effects on epithelial-to-mesenchymal transition
}

\author{
Jian Liu' ${ }^{1,2,3, *}$, Xiao Zheng ${ }^{1,2,3, *}$, Haifeng Deng ${ }^{1,2,3}$, Bin $X \mathbf{u}^{1,2,3}$, Lujun Chen ${ }^{1,2,3}$, Qi \\ Wang $^{1,2,3}$, Qi Zhou ${ }^{4}$, Dachuan Zhang ${ }^{5}$, Changping $\mathbf{W u}^{1,2,4}$ and Jingting Jiang ${ }^{1,2,3}$ \\ ${ }^{1}$ Department of Tumor Biological Treatment, The Third Affiliated Hospital of Soochow University, Changzhou 213003, China \\ 2 Jiangsu Engineering Research Center for Tumor Immunotherapy, Changzhou 213003, China \\ ${ }^{3}$ Institute of Cell Therapy, Soochow University, Changzhou 213003, China \\ ${ }^{4}$ Department of Oncology, The Third Affiliated Hospital of Soochow University, Changzhou 213003, China \\ ${ }^{5}$ Department of Pathology, The Third Affiliated Hospital of Soochow University, Changzhou 213003, China \\ *These authors contributed equally to this work
}

Correspondence to: Jingting Jiang, email: jiangjingting@suda.edu.cn

Keywords: C-C motif chemokine receptor 6 (CCR6); esophageal squamous cell carcinoma (ESCC); lymph node metastasis; epithelial-to-mesenchymal transition (EMT)

Received: September 08, $2017 \quad$ Accepted: November 16, $2017 \quad$ Published: December 15, 2017

Copyright: Liv et al. This is an open-access article distributed under the terms of the Creative Commons Attribution License 3.0 (CC BY 3.0), which permits unrestricted use, distribution, and reproduction in any medium, provided the original author and source are credited.

\section{ABSTRACT}

Esophageal squamous cell carcinoma (ESCC) is the most common esophageal cancer associated with poor prognosis. We detected the expression of C-C motif chemokine receptor 6 (CCR6) and epithelial-to-mesenchymal transition (EMT) markers in esophageal tissues/cells, and evaluated the effects of CCR6 on ESCC cells proliferation, migration and invasion in response to C-C motif chemokine ligand 20 (CCL20) treatment. Our data showed CCR6 was highly expressed in ESCC cell lines (ECA-109 and TE-1), whereas kept in a low expression in normal cell lines HEEC $(P<0.001) . C C L 20$ stimulus induced a significant decrease in the proliferation ability of ESCC $(P<0.05)$. The healing speed of CCL20 group was significantly higher than control in ECA-109 $(P<0.01)$, whereas significantly lower in aCCR6+CCL20 group than CCL20 group $(P<0.05)$. The number of cells permeabling through the polycarbonate membrane in CCL20 group was higher than control $(P<0.01)$. The cell number in aCCR6+CCL20 group was significantly reduced compared to CCL20 group in ECA-109 $(P<0.05)$. Moreover, after CCL20 stimulated in ECA-109, both mRNA and protein level of E-cadherin significantly decreased compared to control, while Vimentin was significantly higher. In aCCR6+CCL20 group, mRNA and protein level of E-cadherin significantly increased compared to CCL20 group, while Vimentin was much lower than CCL20 group. There was no significant difference in TE-1. In summary, high expression of CCR6 existed in the lymph node metastasis and TNM stage of ESCC. CCR6 play an important role in the regulation of tumor cell proliferation, invasion and migration. CCR6 may participate in regulating the occurrence of EMT in ESCC.

\section{INTRODUCTION}

Esophageal cancer (EC) is one of the most common digestive tract malignant tumor in the world, attributing to 478000 incidence (320 800 males and 157200 females) and 375000 deaths (253 800 males and 131300 females) in China in 2015 [1]. The Type of EC in China mainly includes squamous cell carcinoma, adenocarcinoma or undifferentiated carcinoma. About $90 \%$ of EC in China is esophageal squamous cell carcinoma (ESCC), which has rapid progression, strongly local invasive, high rate of relapse and low survival [2]. Though the ESCC can be completely cured if diagnosed early, poor survival and increasing deaths of ESCC patients are mainly due to rapid 
progression and locoregional metastasis recurrence [3]. Therefore, finding and defining the relevant molecular marker signature on ESCC which dictates invasion and metastasis is important to improve the patient's outcome.

Cancer metastasis occurs when genetically unstable cancer cells adapt to a tissue microenvironment that is distant from the primary tumor, is a multi-step process. The process of transition from epithelial cell change into mesenchymal phenotype cell, known as EMT, is closely related to the progress of tumor. EMT in tumor contains primary tumor cells lose the polarity of epithelial cells properties (strong adhesion, lamellar structure), and translate into mesenchymal cells capable of migration and invasion characteristics (no cell polarity, loss the close connection between cells) [4]. A variety of proteins involved in various adherens junctions and cytoskeleton reorganization are regulated in the process. It includes E-cadherin, Vimentin, N-cadherin, $\beta$-catenin and so on [5]. Solving factors that induce EMT would greatly help the development of diagnostic and prognostic markers, as well as better therapy for ESCC.

Many other studies have found that chemokine and chemokine receptor interaction participates in tumor metastasis process including ESCC [6-10]. Especially, the expressions of CCR6 and CCL20 are very high in many human tumors including ESCC $[11,12]$. CCR6-CCL20 axis also has been shown important in many autoimmune [13] and inflammatory diseases [14-16]. In the present study, we find that high CCR6 expression is related to advance ESCC. Furthermore, we find the biological significance of CCR6-CCL20 axis in ESCC and also prove involvement of this axis in EMT, which is known to be involved in poor outcome of ESCC. But the molecular mechanisms for this relation remain elusive.

\section{RESULTS}

\section{Expression of CCR6 in esophageal tissues and cell lines}

Immunostaining of CCR6, E-cadherin and Vimentin were calculated as DAB-positive signals per $\mathrm{mm}^{2}$ of total membrane surface area and cytoplasm of tissue sections, the expression of CCR6 was significantly higher in cancer tissues compared with adjacent normal tissue (Figure 1A). Expression of CCR6 was higher in cases with lymph node-positive and high TNM stage compared with nonmetastatic and low TNM stage cases $(P<0.05)$. Further, expression of E-cadherin was lower in cases with TNM high stage compared with TNM low stage $(P=0.001)$ (Table 1). Our data showed, the expression of CCR6, E-cadherin in esophageal squamous carcinoma with low correlation $(P=0.031)$, and no significant correlation between CCR6 and Vimentin expression $(P=0.492)$ (Table 2).
To further determine the expression of CCR6 mRNA in esophageal cell, two kinds of ESCC cell lines (ECA109 and TE-1) and normal esophageal epithelial cell lines (HEEC) were subjected to qRT-PCR analysis of CCR6 mRNA. Similar to tissue expression, CCR6 mRNA levels were significantly higher in cancer cell lines compared to normal esophageal epithelial cell lines $(P<0.001)$. CCR6 was only expressed at a low level in HEEC (Figure 1B).

\section{CCR6-activation affects proliferation, migration and invasion in EC cells}

CCK-8 assay was used to determine proliferation in untreated and CCL20-treated EC cells. Proliferation of ESCC cell lines significantly decreased $(P<0.05)$ after CCL20 stimulated 24 hours compared with untreated samples. Proliferation ability increased significantly $(P<0.05)$ after blocking CCR6 in ECA-109 cells compared with CCL20 treated group (Figure 2A). The effect of CCR6-CCL20 axis on ESCC cell migration and invasion was characterised by wound healing and trans-well using CCL20 as a chemo-attractant. ESCC cell lines showed higher migratory potential toward CCL20 gradients, compared to respective untreated cells, which was significantly $(P<0.05)$ inhibited after CCR6 blockade in ECA-109 cells not in TE-1 cells (Figure 2B). In contrast, trans-well assay showed that treatment of TE-1 cells with CCL20 and blocking CCR6 did no noticeably alter cell invasion. There were significant difference in invasion between CCL20-treated and untreated cells $(P<0.01)$, also between CCL20-treated and anti-CCR6treated $(P<0.05)$ in ECA-109 cells (Figure 2C).

\section{CCR6-CCL20 interaction affects EMT markers in $\mathrm{EC}$ cells}

EMT promotes cancer cell metastasis and has a negative impact on disease progress and therapeutic outcome. Hence, we evaluated the effect of CCR6-CCL20 interaction on EMT markers (E-cadherin and Vimentin). Reduction in E-cadherin protein and increased in Vimentin protein were observed 1 hour after CCL20 treatment, meanwhile, an opposite results were observed after CCR6 blockade in ECA-109 cell lines, statistical significance of change in protein level of E-cadherin and Vimentin in CCL20 treated cells compared with untreated cells are indicated as ${ }^{*} P<0.05,{ }^{* *} P<0.01$, and the change in protein level of E-cadherin and Vimentin in CCL20-treated cells compared with blocked CCR6 cells are indicated as ${ }^{\#} P<0.05,{ }^{\#} P<0.01$ (Figure 3A-3B). Similar expression pattern after CCL20 treatment and blocked CCR6 were observed at mRNA level by qRT-PCR in ECA-109 cell lines (Figure 4A). EMT markers were not noticeably alter in TE-1 cell lines in either protein or mRNA level (Figures 3C-3D, 4B). 


\section{DISCUSSION}

Cancer metastasis is a multiple and complex process. A variety of chemokine receptors such as CCR7, CCR2, CXCR4, have confirmed its important function in tumor invasion and metastasis [17-19] since Muller et al. [20] reported chemokine receptors were closely related to breast cancer metastasis. CCR6, an important CC subtype chemokine receptor, the main role of CCR6 protein in normal physiology is involved in host defense and the process of antigen presenting during immune response. It was recently confirmed to be associated with progression of various cancers [11, 21], including ESCC [22, 23]. Our immunohistochemistry results showed that the expression of CCR6 in ESCC tissues was higher compared with normal adjacent esophageal tissues. Overexpression of CCR6 in ESCC tissues strongly implies the potential function of CCR6 in metastasis mechanism of ESCC. Higher expression of CCR6 in lymph node-positive cases compared with N0 and higher expression in high TNM stage cases further suggests that CCR6 is a potential marker in ESCC aggressiveness. It can be used as a biomarker for diagnosis and treatment in ESCC. To further establish the biological function of CCR6 in ESCC, its mRNA expression was tested in ESCC cell lines and normal esophageal epithelial cell lines. Higher expression of CCR6 in cancer cells compared with normal cells confirms the clinical significance of CCR6 in ESCC at cellular level.

Abnormal proliferation of tumor cell promotes the progress of tumor, influence the curative effect of treatment. In this study, we found a significant inhibition in proliferation of cell lines (ECA-109 and TE-1) after CCL20 stimulated.
This proliferation inhibition could be due to the cause of CCR6-CCL20 axis in promoting mesenchymal cell transition, which has weaker proliferation ability compared with epithelial cell $[24,25]$. Cancer cells utilize kinds of migratory and invasive approaches in response to the cell external environment. Therefore, exploring the molecular determinants, which promote migratory and invasive of ESCC, can provide a new therapeutic option. Previous research showed that overexpression of CCR6 could promote the invasiveness of cancer cells by interacting with other tumorigenic factors $[11,23,24]$. Our vitro experiments demonstrated that higher migratory potential of EC cell lines in response to chemotactic gradient of CCL20 suggests a role of CCR6-CCL20 axis in ESCC cell migration, and emphasizes the potential of CCR6 as a therapeutic target. It also promoted the invasion of ECA-109 cell lines but not in TE-1 cell lines. Differences between the ESCC cell lines experimental results may be caused by cells differentiation degree and the different expression of CCR6.

Tumor cells need invasion, intravasation, migration and colonization to achieve metastatic goal. Interaction of various signaling pathways influences EMT that promotes these metastatic processes [26]. Chemokine receptor signaling make a significantly contribute in these processes $[27,28]$. EMT is one of main methods to obtain the ability of invasion and metastasis in tumor cells. E-cadherin is a kind of epithelial calcium ions protein that across the membrane. It plays an important function in maintaining the organizational structures and cell polarity. Vimentin is a fibrous protein for maintaining the integrity of the cytoskeleton. Lower expression of E-cadherin and overexpression of Vimentin have a closely relationship with tumor progression $[29,30]$.
A

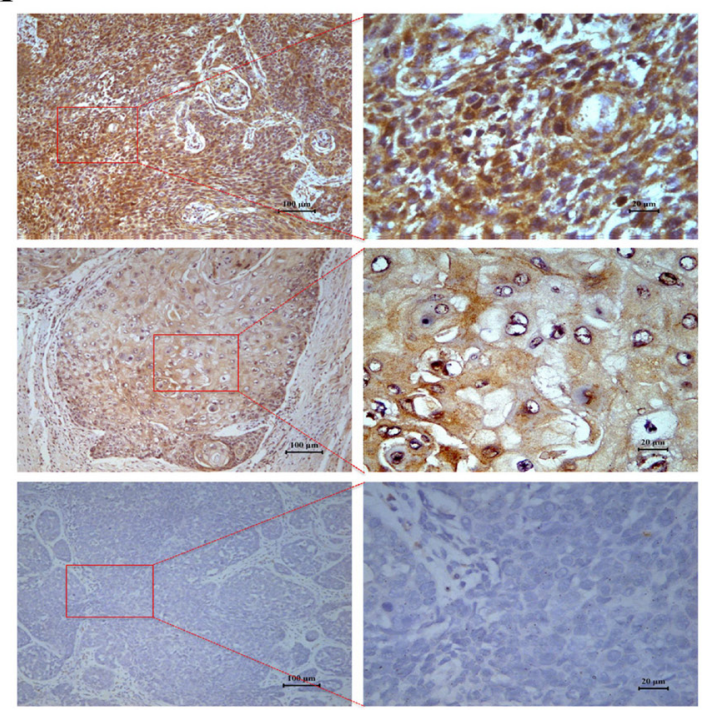

B

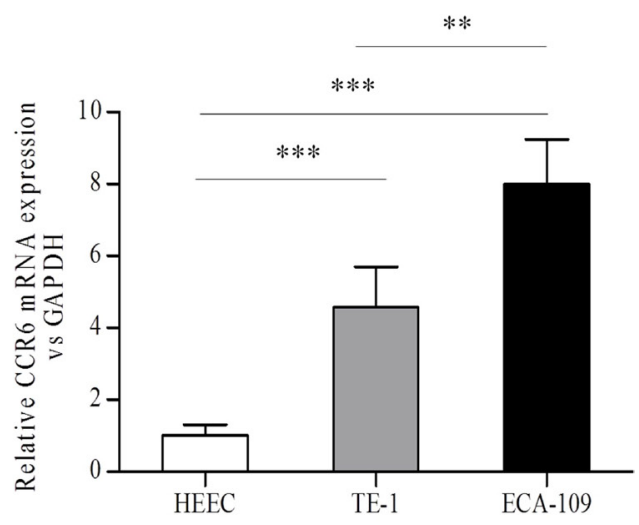

Figure 1: Analysis of CCR6 expression in esophageal tissues and CCR6 mRNA in esophageal cell lines. (A) Immunointensity of CCR6 (brown) in ESCC tissues and normal esophageal tissue. Top two slides represent high immunological staining strength; in the middle two, the immune-staining intensity is moderate, and the bottom two are shown to indicate weak immune-staining. (B) CCR6 mRNA levels were significantly higher in ESCCcells (ECA-109, TE-1) compared to normal esophageal epithelial cells (HEEC). CCR6 mRNA was only expressed at a low level in HEEC. $\left({ }^{* *} P<0.01,{ }^{* * *} P<0.001\right)$. 
Table 1: Correlation of CCR6, E-cadherin and Vimentin expression with clinical data from ESCC patients

\begin{tabular}{|c|c|c|c|c|c|c|c|c|c|c|c|c|}
\hline \multirow[b]{2}{*}{ Parameters } & \multicolumn{2}{|c|}{ CCR6 } & \multirow[b]{2}{*}{$\chi^{2}$} & \multirow[b]{2}{*}{$P$} & \multicolumn{2}{|c|}{ E-cadherin } & \multirow[b]{2}{*}{$\chi^{2}$} & \multirow[b]{2}{*}{$P$} & \multicolumn{2}{|c|}{ Vimentin } & \multirow[b]{2}{*}{$\chi^{2}$} & \multirow[b]{2}{*}{$\boldsymbol{P}$} \\
\hline & - & + & & & - & + & & & - & + & & \\
\hline \multicolumn{13}{|l|}{ Gender } \\
\hline Female & 7 & 12 & 0.916 & 0.339 & 7 & 16 & 0.203 & 0.652 & 13 & 10 & 0.000 & 0.996 \\
\hline Male & 18 & 52 & & & 27 & 49 & & & 43 & 33 & & \\
\hline \multicolumn{13}{|l|}{ Age } \\
\hline$<60$ & 13 & 34 & 0.009 & 0.924 & 17 & 34 & 0.048 & 0.827 & 27 & 24 & 0.562 & 0.453 \\
\hline$\geq 60$ & 12 & 30 & & & 17 & 31 & & & 29 & 19 & & \\
\hline \multicolumn{13}{|c|}{ Tumor size $(\mathrm{cm})$} \\
\hline$<3.5$ & 13 & 22 & 2.340 & 0.126 & 11 & 24 & 0.204 & 0.652 & 18 & 17 & 0.582 & 0.446 \\
\hline$\geq 3.5$ & 12 & 42 & & & 23 & 41 & & & 38 & 26 & & \\
\hline \multicolumn{13}{|l|}{ T stage } \\
\hline $\mathrm{T} 1-\mathrm{T} 2$ & 9 & 21 & 0.082 & 0.775 & 11 & 24 & 0.204 & 0.652 & 22 & 13 & 0.872 & 0.350 \\
\hline $\mathrm{T} 3-\mathrm{T} 4$ & 16 & 43 & & & 23 & 41 & & & 34 & 30 & & \\
\hline \multicolumn{13}{|c|}{ L-node metastasis } \\
\hline Negative & 21 & 37 & 5.431 & $0.020^{*}$ & 25 & 40 & 1.423 & 0.233 & 39 & 26 & 0.909 & 0.340 \\
\hline Positive & 4 & 27 & & & 9 & 25 & & & 17 & 17 & & \\
\hline \multicolumn{13}{|c|}{ Distance metastasis ${ }^{\#}$} \\
\hline Negative & 25 & 59 & - & 0.316 & 33 & 60 & - & 0.661 & 55 & 38 & - & 0.083 \\
\hline Positive & 0 & 5 & & & 1 & 5 & & & 1 & 5 & & \\
\hline \multicolumn{13}{|l|}{ TNM stage } \\
\hline I-I & 21 & 35 & 6.621 & $0.010^{*}$ & 22 & 40 & 11.66 & $0.001^{*}$ & 35 & 27 & 0.001 & 0.976 \\
\hline III-IV & 4 & 29 & & & 12 & 2 & & & 21 & 16 & & \\
\hline
\end{tabular}

CCR6, $n=89$; E-cadherin and Vimentin, $n=99$; Values in bold signify ${ }^{*} P<0.05$. "Fisher's exact test.

Table 2: Correlation of the expression between CCR6, E-cadherin and Vimentin

\begin{tabular}{|c|c|c|c|c|c|}
\hline & & & CCR6 & E-cadherin & Vimentin \\
\hline \multirow[t]{9}{*}{ Spearman's rho } & CCR6 & $\begin{array}{l}\text { Correlation } \\
\text { Coefficient }\end{array}$ & 1.000 & $.224^{*}$ & -.072 \\
\hline & & Sig. (2-tailed) & . & .031 & .492 \\
\hline & & $\mathrm{N}$ & 112 & 93 & 93 \\
\hline & E-cadherin & $\begin{array}{l}\text { Correlation } \\
\text { Coefficient }\end{array}$ & $.224^{*}$ & 1.000 & $-.293^{* *}$ \\
\hline & & Sig. (2-tailed) & .031 & . & .002 \\
\hline & & $\mathrm{N}$ & 93 & 105 & 105 \\
\hline & Vimentin & $\begin{array}{l}\text { Correlation } \\
\text { Coefficient }\end{array}$ & -.072 & $-.293^{* *}$ & 1.000 \\
\hline & & Sig. (2-tailed) & .492 & .002 & . \\
\hline & & $\mathrm{N}$ & 93 & 105 & 105 \\
\hline
\end{tabular}

${ }^{*}$ Correlation is significant at the 0.05 level (2-tailed). ${ }^{* *}$ Correlation is significant at the 0.01 level (2-tailed).

Hence, our western data showed decrease in E-cadherin and increase in Vimentin after CCL20 treatment in ECA-109 cell lines; meanwhile an opposite result of the E-cadherin and Vimentin expression were observed in ECA-109 cell lines after blocking the expression of CCR6. A consistent result was obtained by qRT-PCR detection in mRNA level. There were no significantly different changes in TE-1 cell lines both in protein and gene level. Our results were consistent with previous researches that CCR6 is associated with EMT in various cancers $[23,24,31]$. 
$\mathbf{A}$

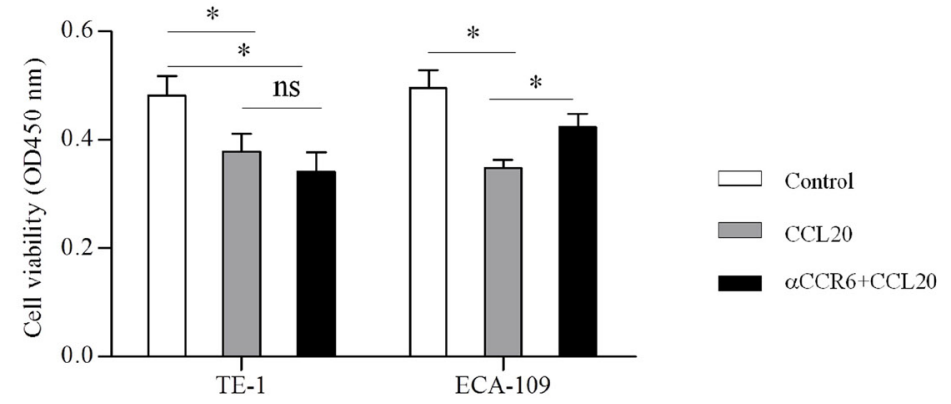

B

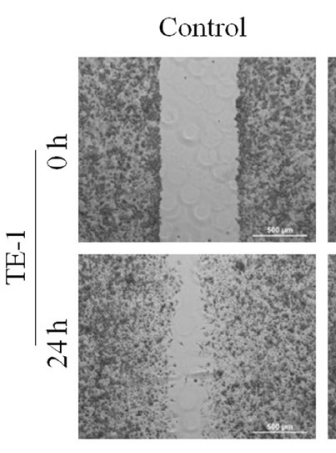

CCL20

$\alpha \mathrm{CCR} 6+\mathrm{CCL} 20$
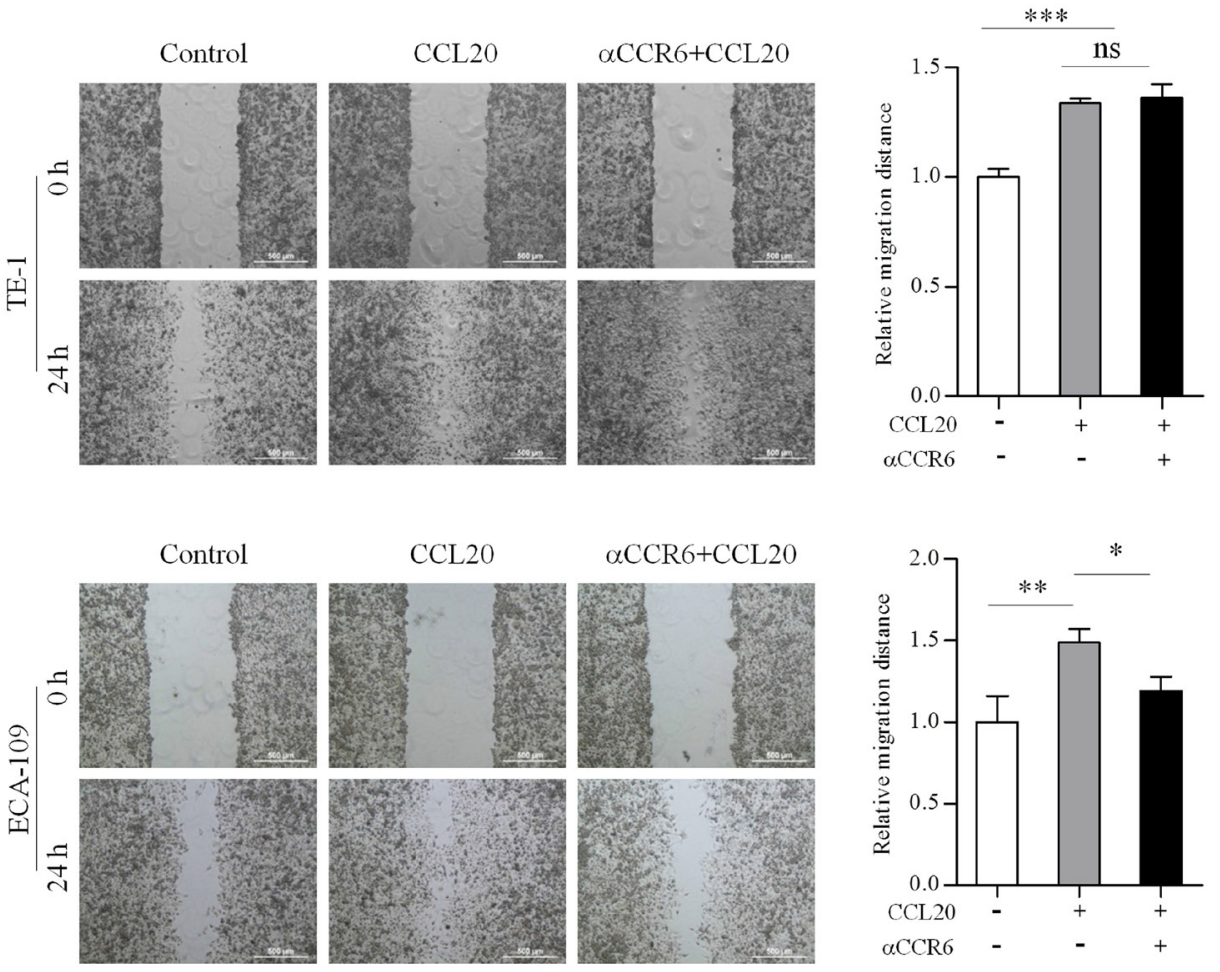

CCL20

$\alpha \mathrm{CCR} 6+\mathrm{CCL} 20$
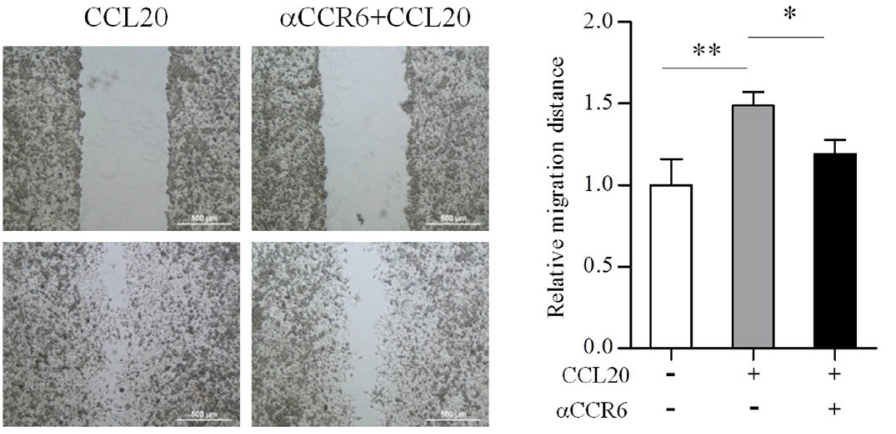

C
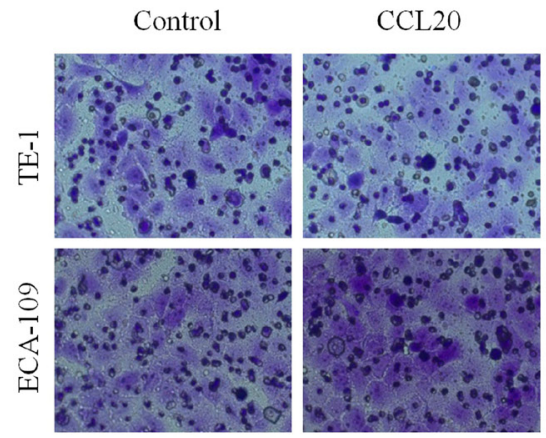

$\alpha \mathrm{CCR} 6+\mathrm{CCL} 20$

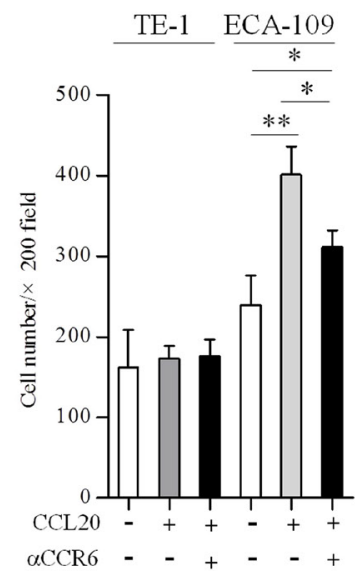

Figure 2: CCR6-activation affects proliferation, migration and invasion in ESCC cells. (A) CCR6-CCL20 interaction inhibited proliferation of ESCC cells and promoted migration of ESCC cells. Proliferation of CCL20 treated and blocked CCR6 compared with untreated cells in ECA-109 and TE-1 cells after stimulated 24 hours are shown. (B) The healing speed of CCL20 treated and blocked CCR6 compared with untreated cells in ECA-109 and TE-1 cells after scratched 24 hours are shown. (C) ECA-109 cells showed higher invasive potential after CCL20 stimulated, compared to respective untreated cells and CCR6 blockade cells. Invasion was no significant difference in TE-1 cells. $\left({ }^{*} P<0.05,{ }^{* *} P<0.01,{ }^{* * *} P<0.001\right)$. 
In conclusion, we found that overexpression of CCR6 in ESCC tissues and cell lines compared with normal adjacent tissue and normal esophageal epithelium cell lines. The differences of the CCR6 expression and the functional experimental study between esophageal cancer cell lines ECA-109 and TE-1 may be caused by the different degrees of differentiation in the ESCC cell lines. The expression of CCR6 in ESCC was significantly associated with nodal status and TNM stage. Inhibition of cell proliferation after CCL20 stimulated and activation of EMT markers, high migratory and invasive potential implicates association of CCR6-CCL20 with ESCC (ECA-109 cell lines) progresses. Although CCR6 and its ligand in the molecular mechanism of ESCC progress and function research is not clear. But

A

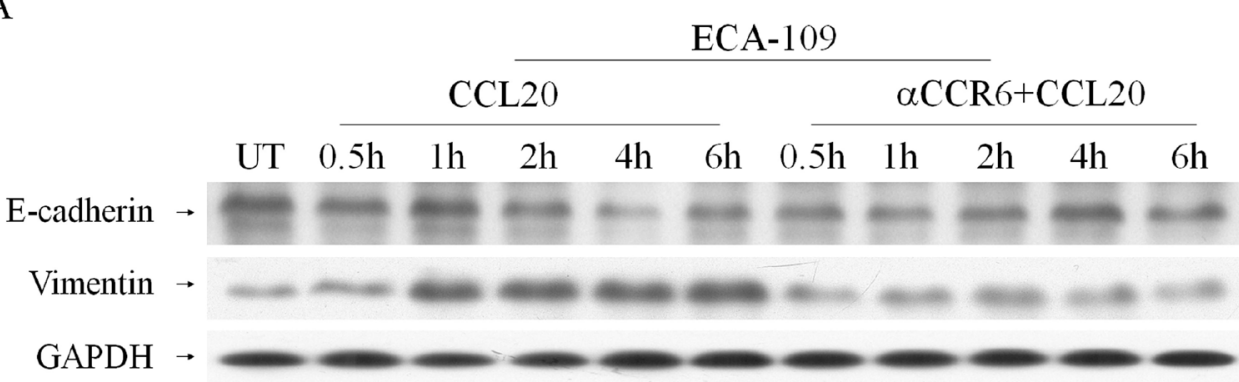

B

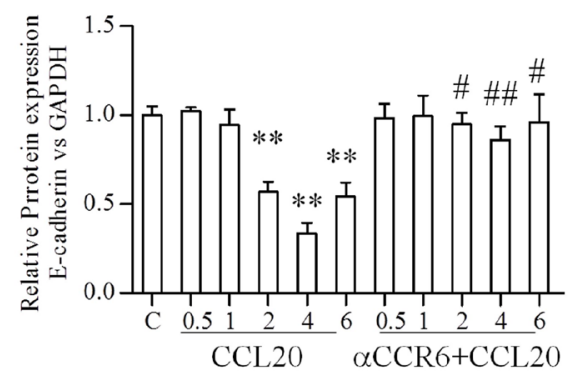

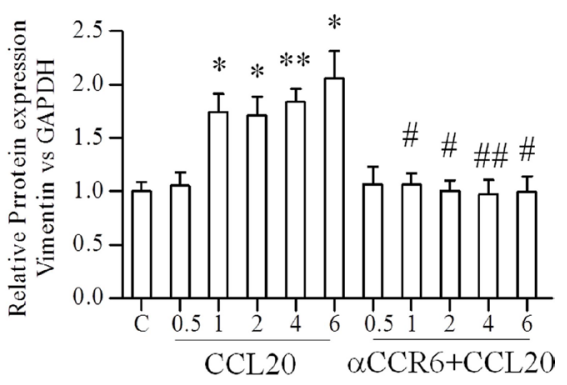

C

TE-1

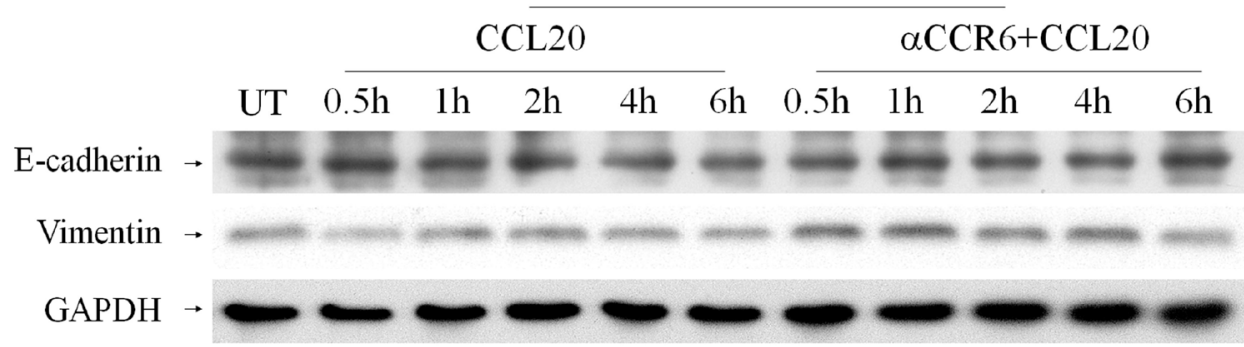

D
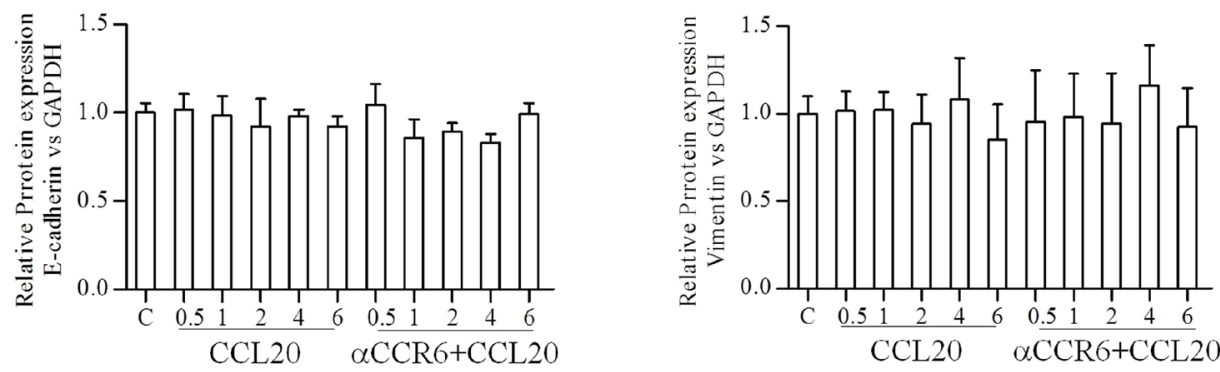

Figure 3: Effects of CCR6-CCL20 interactions on EMT of ESCC cell on protein level. (A-D) The protein expression changes of E-cadherin and Vimentin in ESCC cell lines: ECA-109 (A, B), TE-1(C, D) after CCL20 treating and blocking CCR6 were showed. GAPDH was used as a loading control. ( ${ }^{*} P<0.05,{ }^{* *} P<0.01,{ }^{\#} P<0.05,{ }^{\# \#} P<0.01$ ). 
with the deepening research of the CCR6 biology function, CCR6 and CCR6-CCL20 axis are expected to become new targets for treatment of ESCC, and provide a new strategy in inhibition of tumor growth and metastasis.

\section{MATERIALS AND METHODS}

\section{Tissue specimens}

Tissue microarray (TMA) was purchased from commercial source (Outdo Biotech Co. Ltd.). TMA contains EC tissue samples were obtained from 99 patients (76 males and 23 females, median age 59 years, range 37-78), who underwent esophageal resection for cancer with curative intent at the Department of Thoracic surgery, University of The Third Affiliated Hospital of Soochow between 2005 and 2006, and 11 cases of adjacent normal tissues. Clinical data was collected from the pathography of patients. All the clinical samples were approved by ethics committee of the third affiliated hospital of soochow university.

\section{Tissue chip}

Read the H\&E-stained histological slices of all ESCC cases again, and make marks in slices and the original wax blocks. Use $0.6 \mathrm{~mm}$ diameter suction needle suck organization from the wax block by tissue chip instrument, then loads in the position of receptor wax block according

A

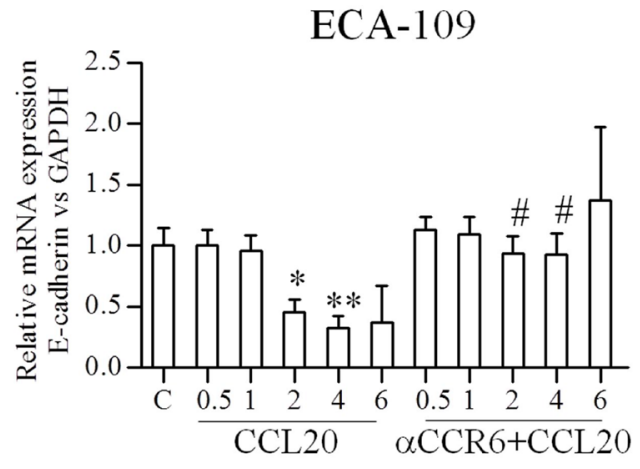

$\mathrm{B}$

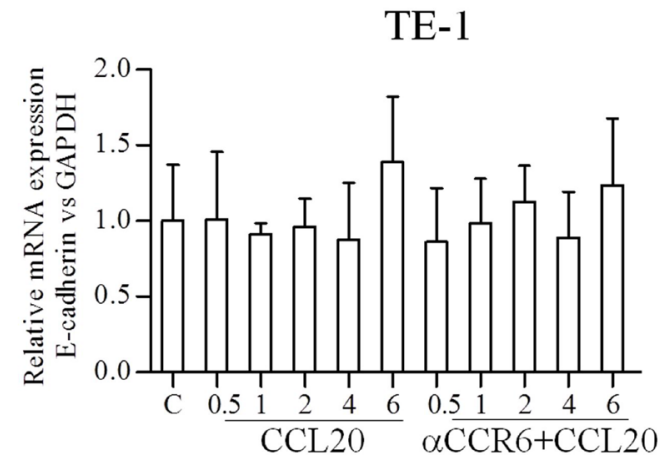

to the upfront design arrangement order. Drilled hole on the preparation blank paraffin block according to the number of sample and the required size of the organization, arranged in array. Successive $3 \mu \mathrm{m}$ slices lay on glass deal by Poly-LLysine after wax blocks were prepared.

\section{Immunohistochemistry}

Esophageal TMA, containing cancer and normal adjacent tissues, were stained for CCR6, E-cadherin and Vimentin. Sections were deparaffinized three times for $15 \mathrm{~min}$ each in xylene. Sections were rehydrated for $5 \mathrm{~min}$ each in decreasing concentrations of ethanol (100\%, 95\% and 75\%), followed by antigen retrieval in high temperature water, and washed in PBS three times. The sections were incubated with $3 \% \mathrm{H}_{2} \mathrm{O}_{2}$ in PBS for $10 \mathrm{~min}$ for blocking endogenous peroxidase, rinsed three times with PBS, blocked with 3\% BSA at RT for $20 \mathrm{~min}$, and then incubated with primary antibodies at $4{ }^{\circ} \mathrm{C}$ overnight in humidity chamber (E-cadherin, 1:500, MAB-0589, Maixin; Vimentin, 1:500, MAB-0178, Maixin; CCR6 antibody, 1:500, MAB195, R\&D). Next, washed the sections with PBS and incubated with HRP-labeled goat anti-mouse/ rabbit secondary antibody (KIT-5020, Maixin) for 1 hour at room temperature (RT). Diaminobenzidine was used as the chromogen and hematoxylin for the nuclear counterstain. Subsequently, the sections were dehydrated,
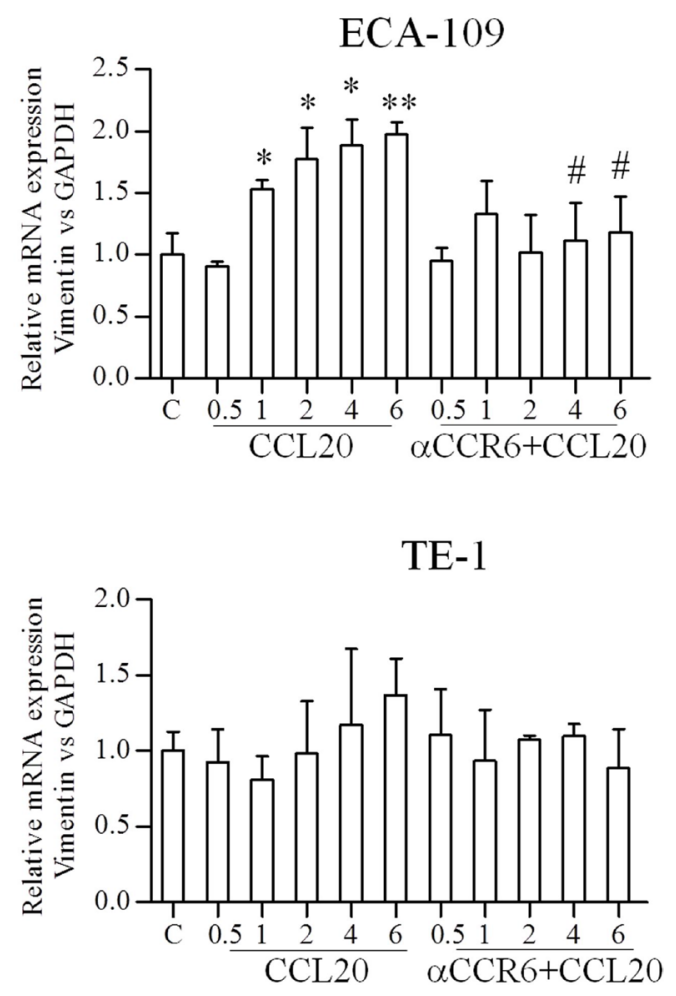

Figure 4: Effects of CCR6-CCL20 interactions on EMT of ESCC cell on mRNA level. (A, B) QRT-PCR analysis was used to confirm E-cadherin and Vimentin protein expression results on mRNA level. GAPDH was used as a loading control. $\left({ }^{*} P<0.05\right.$, $\left.{ }^{* *} P<0.01,{ }^{\#} P<0.05\right)$. 
Table 3: The sequences of PCR primers used in this study

\begin{tabular}{lrr}
\hline Gene & \multicolumn{1}{c}{ Forward primer } & Reverse primer \\
\hline CCR6 & 5'-TTCAGCGATGTTTTCGACTCC-3' & 5'-GCAATCGGTACAAATAGCCTGG-3' \\
E-cadherin & 5'-CGAGAGCTACACGTTCACGG-3' & 5'-GGGTGTCGAGGGAAAAATAGG-3' \\
Vimentin & 5'-AGTCCACTGAGTACCGGAGAC-3' & 5'-CATTTCACGCATCTGGCGTTC-3' \\
GAPDH & 5'-TGTGGGCATCAATGGATTTGG-3' & 5'-TGTGGGCATCAATGGATTTGG-3' \\
\hline
\end{tabular}

cleared and mounted. The immunostaining intensity of CCR6 and E-cadherin were assessed according to the $H$-score method described by our previous report [32]: $H$-score $=(\%$ unstained $\times 0)+(\%$ stained weak $\times 1)$ $+(\%$ stained moderate $\times 2)+(\%$ stained strong $\times 3)$. The $H$-scores ranged from $0(100 \%$ negative) to $300(100 \%$ strong staining). For the evaluation of Vimentin staining, the rate of Vimentin positive cancer cells in all cancer cells was calculated and the positive rate was recorded.

\section{Cell culture and treatment}

The esophageal cancer cell lines (ECA-109 and TE-1) and normal esophageal epithelial cell lines (HEEC) (The cell bank, Chinese academy of sciences) were used for study. Cell lines were cultured in RPMI 1640 (10\% fetal calf serum, $100 \mathrm{U} / \mathrm{ml}$ penicillin, $100 \mu \mathrm{g} / \mathrm{ml}$ streptomycin) (Gibco). All cell lines were cultured at $5 \% \mathrm{CO}_{2}, 37^{\circ} \mathrm{C}$.

\section{RNA extraction and real-time PCR}

ESCC cell lines $\left(2.5 \times 10^{6} /\right.$ well $)$ were seeded in 96 well plates. After overnight culture, cells were treated with CCL20 $(100 \mathrm{ng} / \mathrm{ml})$ for different time intervals $(0.5,1,2,4,6)$ hours. Untreated cells were used as negative control. Total cellular RNA was extracted from cell lines using Trizol reagent according to the instructions of the manufacturer (Takara Bio). Nanodrop2000 was used to test the absorbance in $260 \mathrm{~nm} / 280 \mathrm{~nm}$, and then calculated concentration and purity, preserved in $-80^{\circ} \mathrm{C}$. cDNA was synthesized using GoScript-TM. Reverse Transcription system according to the manufacturer's instructions (Promega). The relative expressions of EMT markers (E-cadherin and Vimentin), CCR6 and control GAPDH were continuously detected during 40 cycles by real-time PCR in 7500HT fast real-time PCR system (Applied Biosystems). Experiment was repeated three times. Specific primers and probes were obtained from Sangon Biotech. The sequences are in following Table 3.

\section{Proliferation assay}

ESCC cells were seeded at a density of $100 \mu \mathrm{l}$ $1 \times 10^{4} /$ well in 96 well plates, and then incubation at $5 \%$ $\mathrm{CO}_{2}, 37^{\circ} \mathrm{C}$ overnight. Cells were stimulated with $100 \mu \mathrm{l}$ recombinant CCL20 (360-MP-025, R\&D) or aCCR6 (ab68131, Abcam) + CCL20, incubated 36 hours. Next, $10 \mu \mathrm{l}$ CCK-8 reagent was added to the cells and incorporated CCK-8 was detected using Thermo Scientific Multiskan at A450 nm after 1 hour. Growth curve was drew with A450 average as the ordinate, time as the abscissa.

\section{Migration assay}

Wound healing experiment was used for migration study. 96 well plates were packaged with FN $(10 \mu \mathrm{g} / \mu \mathrm{l})$ and incubation at $37^{\circ} \mathrm{C}$ overnight. Aspiration the solution and dry the plate in the next day. ESCC cells $\left(5 \times 10^{5}\right)$ with or without blocking CCR6 used $\alpha$ CCR6 $(1 \mu \mathrm{g} / \mathrm{ml})$ and CCL20 $(100 \mathrm{ng} / \mathrm{ml})$ were added in the well with DMEM, and then incubated at $5 \% \mathrm{CO}_{2}, 37^{\circ} \mathrm{C}$ overnight. $1 \mathrm{ml}$ sterilization spear was scratched the bottom of culture plates vertically, uniformly and quickly. Took photos and measured the scratch width after 0 hour, 24 hours. According to the collected data analyzed the results and drew pictures.

\section{Invasion assay}

Trans-well experiment was used for invasion study. ESCC cells $\left(2 \times 10^{4}\right)$ with EMDM were added to the top chamber. DMEM with or without blocking CCR6 used $1 \mu \mathrm{g} / \mathrm{ml} \alpha$ CCR 6 and $100 \mathrm{ng} / \mathrm{ml} \mathrm{CCL20} \mathrm{were} \mathrm{added} \mathrm{in}$ the bottom chamber. Cells were then allowed to invade under chemotactic of CCL20 at $5 \% \mathrm{CO}_{2}, 37^{\circ} \mathrm{C}$ overnight. Wiped out Non-invaded cells from top chamber with cotton swab. Cells at the bottom surface were fixed with $100 \%$ methanol for $20 \mathrm{~min}$, stained for 2 hours with crystal violet, and rinsed three times with PBS. Invaded cells were counted under the microscope at $40 \times$ magnification.

\section{Western blot assay}

The relative levels of EMT markers (E-cadherin and Vimentin) were further confirmed by western blot analyses. ESCC cells were treated with $100 \mathrm{ng} / \mathrm{ml}$ CCL20, cell lysates were prepared using protease inhibitor cocktail containing RIPA buffer (Thermo Fisher Scientific, USA) at different time points (0.5, 1, 2, 4 and 6 hours) after CCL20 treatment. The control was the Proteins isolated from untreated cells. E-cadherin was resolved using $6 \%$ SDS-PAGE while Vimentin and GAPDH used 
$10 \%$ SDS-PAGE and transferred electrophoresis onto PVDF membrane. Used 5\% skimmed milk to block the membranes for 2 hours at RT, and probed with primary anti-E-cadherin antibody (ab1416, Abcam), Anti-Vimentin antibody (ab92549, Abcam) at $4^{\circ} \mathrm{C}$ overnight. Membranes were incubated with peroxidase-conjugated anti-rabbit IgG secondary antibody (Beyotime) at RT for 1 hour. Immunoreactive protein bands were visualized with EZECL Kit (Biolnd Biotech).

\section{Statistical analysis}

All statistical analyses were performed by using SPSS 22.0 software (SPSS, Inc., Chicago, IL) and GraphPad Prism 5.0 software package (GraphPad Software, Inc., San Diego, USA). ' $t$-test and oneway ANOVA were used to compare the means of two groups or more than two groups respectively, and Chi-square test was used to compare the ratio between different groups. Different groups of nonnormal distribution data were compared by Kruskal-Wallis Test and Mann-Whitney $U$ Test. The $P$ value of less than 0.05 based on the two-sided test was considered to be statistically significant.

\section{Abbreviations}

ESCC: Esophageal squamous cell carcinoma; EC: Esophageal cancer; CCR6: C-C motif chemokine receptor 6; CCL20: C-C motif chemokine ligand 20; EMT: Epithelial-to-mesenchymal transition; TNM: Tumor Node Metastasis; TMA: Tissue microarray; RT: Room temperature; FN: Fibronectin; DMEM: Dulbecco's Modified Eagle's Medium.

\section{Author contributions}

Jian Liu, Xiao Zheng, Changping Wu and Jingting Jiang conceptional design and writing of the draft manuscript. Haifeng Deng, Lujun Chen, Qi Wang and Qi Zhou acquired and examined the clinical data of this study. Bin Xu and Dachuan Zhang performed Statistical analyses.

\section{ACKNOWLEDGMENTS}

We thank the patients and their families.

\section{CONFLICTS OF INTEREST}

The authors declare that they have no conflicts of interest.

\section{FUNDING}

This study was supported by grants from the National Key Technology R\&D Program (2015BAI12B12), the
National Natural Science Foundation of China (No. 31570877 and 31570908 ), Jiangsu Engineering Research Center for Tumor Immunotherapy (BM2014404), Jiangsu Key Laboratory of Medical Science and Laboratory Medicine (JSKLM-2014-003), the Key R\&D Project of Science and Technology Department of Jiangsu Province (BE2015633 and BE2016660), and Changzhou Science and Technology Project (Applied Based Research, No. CJ20160021).

\section{REFERENCES}

1. Chen W, Zheng R, Baade PD, Zhang S, Zeng H, Bray F, Jemal A, Yu XQ, He J. Cancer statistics in China, 2015. CA Cancer J Clin. 2016; 66:115-32. https://doi.org/10.3322/ caac. 21338 .

2. Engel LS, Chow WH, Vaughan TL, Gammon MD, Risch HA, Stanford JL, Schoenberg JB, Mayne ST, Dubrow R, Rotterdam H, West AB, Blaser M, Blot WJ, et al. Population attributable risks of esophageal and gastric cancers. J Natl Cancer Inst. 2003; 95:1404-13.

3. Ma DY, Tan BX, Liu M, Li XF, Zhou YQ, Lu Y. Concurrent three-dimensional conformal radiotherapy and chemotherapy for postoperative recurrence of mediastinal lymph node metastases in patients with esophageal squamous cell carcinoma: a phase 2 single-institution study. Radiat Oncol. 2014; 9:28. https://doi.org/10.1186/1748-717X-9-28.

4. Thiery JP, Acloque H, Huang RY, Nieto MA. Epithelialmesenchymal transitions in development and disease. Cell. 2009; 139:871-90. https://doi.org/10.1016/j.cell.2009.11.007.

5. Iwatsuki M, Mimori K, Yokobori T, Ishi H, Beppu T, Nakamori S, Baba H, Mori M. Epithelial-mesenchymal transition in cancer development and its clinical significance. Cancer Sci. 2010; 101:293-9. https://doi. $\operatorname{org} / 10.1111 / \mathrm{j} .1349-7006.2009 .01419 . x$.

6. Behnam Azad B, Lisok A, Chatterjee S, Poirier JT, Pullambhatla M, Luker GD, Pomper MG, Nimmagadda S. Targeted Imaging of the Atypical Chemokine Receptor 3 (ACKR3/CXCR7) in Human Cancer Xenografts. J Nucl Med. 2016; 57:981-8. https://doi.org/10.2967/jnumed.115.167932.

7. Lukaszewicz-Zajac M, Mroczko B, Kozlowski M, Szmitkowski M. The Serum Concentrations of Chemokine CXCL12 and Its Specific Receptor CXCR4 in Patients with Esophageal Cancer. Dis Markers. 2016; 2016:7963895. https://doi.org/10.1155/2016/7963895.

8. Lukaszewicz-Zajac M, Mroczko B, Szmitkowski M. Chemokines and their receptors in esophageal cancer - the systematic review and future perspectives. Tumour Biol. 2015; 36:5707-14. https://doi.org/10.1007/s13277-015-3705-7.

9. Shi M, Chen D, Yang D, Liu XY. CCL21-CCR7 promotes the lymph node metastasis of esophageal squamous cell carcinoma by up-regulating MUC1. J Exp Clin Cancer Res. 2015; 34:149. https://doi.org/10.1186/s13046-015-0268-9.

10. Ogura M, Takeuchi H, Kawakubo H, Nishi T, Fukuda K, Nakamura R, Takahashi T, Wada N, Saikawa Y, Omori T, 
Miyasho T, Yamada S, Kitagawa Y. Clinical significance of CXCL-8/CXCR-2 network in esophageal squamous cell carcinoma. Surgery. 2013; 154:512-20. https://doi. org/10.1016/j.surg.2013.06.013.

11. Lu E, Su J, Zhou Y, Zhang C, Wang Y. CCL20/CCR6 promotes cell proliferation and metastasis in laryngeal cancer by activating p38 pathway. Biomed Pharmacother. 2017; 85:486-92. https://doi.org/10.1016/j.biopha.2016.11.055.

12. Liu B, Jia Y, Ma J, Wu S, Jiang H, Cao Y, Sun X, Yin X, Yan S, Shang M, Mao A. Tumor-associated macrophagederived CCL20 enhances the growth and metastasis of pancreatic cancer. Acta Biochim Biophys Sin (Shanghai). 2016; 48:1067-74. https://doi.org/10.1093/abbs/gmw101.

13. Comerford I, Bunting M, Fenix K, Haylock-Jacobs S, Litchfield W, Harata-Lee Y, Turvey M, Brazzatti J, Gregor C, Nguyen P, Kara E, McColl SR. An immune paradox: how can the same chemokine axis regulate both immune tolerance and activation?: CCR6/CCL20: a chemokine axis balancing immunological tolerance and inflammation in autoimmune disease. Bioessays. 2010; 32:1067-76. https:// doi.org/10.1002/bies.201000063.

14. Lee AY, Eri R, Lyons AB, Grimm MC, Korner H. CC Chemokine Ligand 20 and Its Cognate Receptor CCR6 in Mucosal T Cell Immunology and Inflammatory Bowel Disease: Odd Couple or Axis of Evil? Front Immunol. 2013; 4: 194. https://doi.org/10.3389/fimmu.2013.00194.

15. Koga T, Otomo K, Mizui M, Yoshida N, Umeda M, Ichinose K, Kawakami A, Tsokos GC. Calcium/Calmodulin-Dependent Kinase IV Facilitates the Recruitment of Interleukin-17Producing Cells to Target Organs Through the CCR6/CCL20 Axis in Th17 Cell-Driven Inflammatory Diseases. Arthritis Rheumatol. 2016; 68:1981-8. https://doi.org/10.1002/ art.39665.

16. Cheluvappa R. Experimental appendicitis and appendectomy modulate the CCL20-CCR6 axis to limit inflammatory colitis pathology. Int J Colorectal Dis. 2014; 29:1181-8. https://doi.org/10.1007/s00384-014-1936-5.

17. Xu B, Zhou M, Qiu W, Ye J, Feng Q. CCR7 mediates human breast cancer cell invasion, migration by inducing epithelialmesenchymal transition and suppressing apoptosis through AKT pathway. Cancer Med. 2017; 6:1062-71. https://doi. org/10.1002/cam4.1039.

18. Giopanou I, Lilis I, Papaleonidopoulos V, Agalioti T, Kanellakis NI, Spiropoulou N, Spella M, Stathopoulos GT. Tumorderived osteopontin isoforms cooperate with TRP53 and CCL2 to promote lung metastasis. Oncoimmunology. 2017; 6:e1256528. https://doi.org/10.1080/2162402X.2016.1256528.

19. Irawan C, Atmakusumah D, Siregar NC, Tean TB, Kong LW, Kiat OC, Abdulmuthalib A, Harahap A, Mansyur M. Expression of Biomarkers CXCR4, IL11-RA, TFF1, MLF1P in Advanced Breast Cancer Patients with Bone Metastatic: a Diagnostic Study. Acta Med Indones. 2016; 48:261-8.

20. Muller A, Homey B, Soto H, Ge N, Catron D, Buchanan ME, McClanahan T, Murphy E, Yuan W, Wagner SN, Barrera JL, Mohar A, Verastegui E, et al. Involvement of chemokine receptors in breast cancer metastasis. Nature. 2001; 410:50-6. https://doi.org/10.1038/35065016.

21. Du D, Liu Y, Qian H, Zhang B, Tang X, Zhang T, Liu W. The effects of the CCR6/CCL20 biological axis on the invasion and metastasis of hepatocellular carcinoma. Int J Mol Sci. 2014; 15:6441-52. https://doi.org/10.3390/ ijms 15046441 .

22. Chen D, Jiang R, Mao C, Shi L, Wang S, Yu L, Hu Q, Dai D, Xu H. Chemokine/chemokine receptor interactions contribute to the accumulation of Th17 cells in patients with esophageal squamous cell carcinoma. Hum Immunol. 2012; 73:1068-72. https://doi.org/10.1016/j.humimm.2012.07.333.

23. Mishan MA, Heirani-Tabasi A, Mokhberian N, Hassanzade M, Kalalian Moghaddam H, Bahrami AR, Ahmadiankia N. Analysis of Chemokine Receptor Gene Expression in Esophageal Cancer Cells Compared with Breast Cancer with Insights into Metastasis. Iran J Public Health. 2015; 44:1353-8.

24. Kapur N, Mir H, Clark Iii CE, Krishnamurti U, Beech DJ, Lillard JW, Singh S. CCR6 expression in colon cancer is associated with advanced disease and supports epithelial-tomesenchymal transition. Br J Cancer. 2016; 114:1343-51. https://doi.org/10.1038/bjc.2016.113.

25. Liu S, Cong Y, Wang D, Sun Y, Deng L, Liu Y, MartinTrevino R, Shang L, McDermott SP, Landis MD, Hong S, Adams A, D'Angelo R, et al. Breast cancer stem cells transition between epithelial and mesenchymal states reflective of their normal counterparts. Stem Cell Reports. 2014; 2:78-91. https://doi.org/10.1016/j.stemcr.2013.11.009.

26. Kim MA, Lee HS, Lee HE, Kim JH, Yang HK, Kim WH. Prognostic importance of epithelial-mesenchymal transition-related protein expression in gastric carcinoma. Histopathology. 2009; 54:442-51. https://doi.org/10.1111/j.1365-2559.2009.03247.x.

27. Wyler L, Napoli CU, Ingold B, Sulser T, Heikenwalder M, Schraml P, Moch H. Brain metastasis in renal cancer patients: metastatic pattern, tumour-associated macrophages and chemokine/chemoreceptor expression. Br J Cancer. 2014; 110:686-94. https://doi.org/10.1038/bjc.2013.755.

28. Balkwill FR. The chemokine system and cancer. J Pathol. 2012; 226:148-57. https://doi.org/10.1002/path.3029.

29. Kim K, Lu Z, Hay ED. Direct evidence for a role of betacatenin/LEF-1 signaling pathway in induction of EMT. Cell Biol Int. 2002; 26:463-76.

30. Jeanes A, Gottardi CJ, Yap AS. Cadherins and cancer: how does cadherin dysfunction promote tumor progression? Oncogene. 2008; 27:6920-9. https://doi.org/10.1038/ onc.2008.343.

31. Zhang J, Zhu D, Lv Q, Yi Y, Li F, Zhang W. The key role of astrocyte elevated gene-1 in CCR6-induced EMT in cervical cancer. Tumour Biol. 2015; 36:9763-7. https://doi. org/10.1007/s13277-015-3760-0.

32. Liu J, Chen L, Deng H, Xu B, Li M, Zheng X, Wu C, Jiang J. Epithelial-to-mesenchymal transition in human esophageal cancer associates with tumor progression and patient's survival. Int J Clin Exp Pathol. 2014; 7:6943-9. 